\title{
Correlation of Hydrogen Generation with Sparking Discharges in a Mineral Insulating Oil
}

DOI:

10.1109/MEl.2018.8345356

\section{Document Version}

Accepted author manuscript

Link to publication record in Manchester Research Explorer

\section{Citation for published version (APA):}

Xiang, J., Zhou, X., Liu, Q., Wang, Z., Hinshaw, J., \& Mavrommatis, P. (2018). Correlation of Hydrogen Generation with Sparking Discharges in a Mineral Insulating Oil. IEEE Electrical Insulation Magazine, 34(3), 7-12.

https://doi.org/10.1109/MEI.2018.8345356

\section{Published in:}

IEEE Electrical Insulation Magazine

\section{Citing this paper}

Please note that where the full-text provided on Manchester Research Explorer is the Author Accepted Manuscript or Proof version this may differ from the final Published version. If citing, it is advised that you check and use the publisher's definitive version.

\section{General rights}

Copyright and moral rights for the publications made accessible in the Research Explorer are retained by the authors and/or other copyright owners and it is a condition of accessing publications that users recognise and abide by the legal requirements associated with these rights.

\section{Takedown policy}

If you believe that this document breaches copyright please refer to the University of Manchester's Takedown Procedures [http://man.ac.uk/04Y6Bo] or contact uml.scholarlycommunications@manchester.ac.uk providing relevant details, so we can investigate your claim.

\section{OPEN ACCESS}




\title{
Correlation of Hydrogen Generation with Sparking Discharges in a Mineral Insulating Oil
}

Key words: Sparking discharge, dissolved gas analysis, hydrogen, mineral oil

\author{
J. Xiang', X.Y. Zhou', Q. Liu ${ }^{1 *}$, Z.D. Wang1, J. Hinshaw ${ }^{2}$ and P. Mavrommatis ${ }^{3}$ \\ ${ }^{1}$ The University of Manchester, Manchester M13 9PL, UK \\ ${ }^{2}$ Serveron ${ }^{\circledR}$ Corporation, Beaverton, OR 97006, USA \\ ${ }^{3}$ TJ/H2b Analytical Services Ltd, Capenhurst, Chester, CHI 6ES, UK
}

The results of a study of hydrogen generation in a mineral oil under well-controlled sparking faults are presented.

\section{Introduction}

Dissolved gas analysis (DGA) of transformer oil is one of the key methods of assessing transformer health [1]. Transformers operate under multiple stresses, e.g., thermal, electrical and mechanical. The hydrocarbon molecules of transformer oils can be degraded into combustible and incombustible gases under high thermal and electrical stresses, particularly under fault conditions. Different generated gases correspond to specific fault types and levels, e.g., hydrogen is the primary indicator of corona partial discharge, and acetylene is the primary indicator of sparking discharge and high-energy breakdown [2], [3]. DGA technology is therefore widely used to reveal incipient transformer faults by measuring the concentration of fault gases in the transformer oil.

Gas concentrations in transformer oil increase with fault development, and early detection of fault gases can avoid catastrophic transformer failures. On-line DGA monitors can be installed in the oil circulation loop of a transformer in order to monitor fault gas concentrations in the transformer oil continuously. When the concentration or the increasing rate of fault gas generation exceeds a threshold value, an on-line DGA monitor can send an alarm signal to the transformer asset manager [4].

On-line DGA monitors are available in multi-gas and single-gas versions. Multi-gas monitors measure multiple gases e.g., hydrogen, methane, ethane, ethylene and acetylene, while single gas monitors usually monitor only the hydrogen concentration. 
Several techniques are utilised for measuring dissolved hydrogen concentration in oil. Early development of hydrogen monitors was based on a Teflon membrane and a fuel cell. Hydrogen passes through the membrane and undergoes redox reaction with the oxygen in the fuel cell, producing a current proportional to the hydrogen concentration. This type of monitor needs periodic replacement of the membrane and fuel cell [5]. More recent hydrogen monitors use a palladium sensor without a membrane. Palladium is intrinsically selective for hydrogen. When hydrogen diffuses onto the surface of a palladium sensor, the lattice structure of the palladium is changed and forms palladium hydride [6]. Changes in electrical resistance reflect the hydrogen concentration. This type of monitor does not consume hydrogen and offers a lower hydrogen detection limit.

Hydrogen generation in transformer oil varies under different transformer faults. It has been suggested in previous studies [7]-[10] that under partial discharge (PD) fault conditions, hydrogen generation increases with PD intensity. Under sparking fault conditions, hydrogen generation is assumed to increase with increasing number of sparks.

In this article we present the results of an experimental study of the correlation between hydrogen generation and sparking discharges in a mineral oil, using online hydrogen monitors. Sparking discharges were generated using a compact impulse spark generator with accurately controlled spark number and time interval between consecutive sparks. The spark fault energy was calculated from recordings of the voltage and current waveforms. The generated hydrogen volume per unit spark fault energy was calculated under different sparking conditions.

\section{Experimental}

\subsection{Experimental setup}

The experimental setup used to perform DGA measurements under spark faults is shown in Figure 1. A $90 \mathrm{kV}$ compact impulse generator was used to generate the electrical sparks, and a $100 \mathrm{kV}$ voltage divider was used to measure the voltage signals. A current shunt (10 $\Omega)$ was placed at the low voltage side of the test cell to measure the current signals. A National Instruments (NI) high-speed digitizer was used to record the voltage and current signals automatically, and an NI DAQ system was used to control accurately the spark numbers and the time interval between consecutive sparks. 


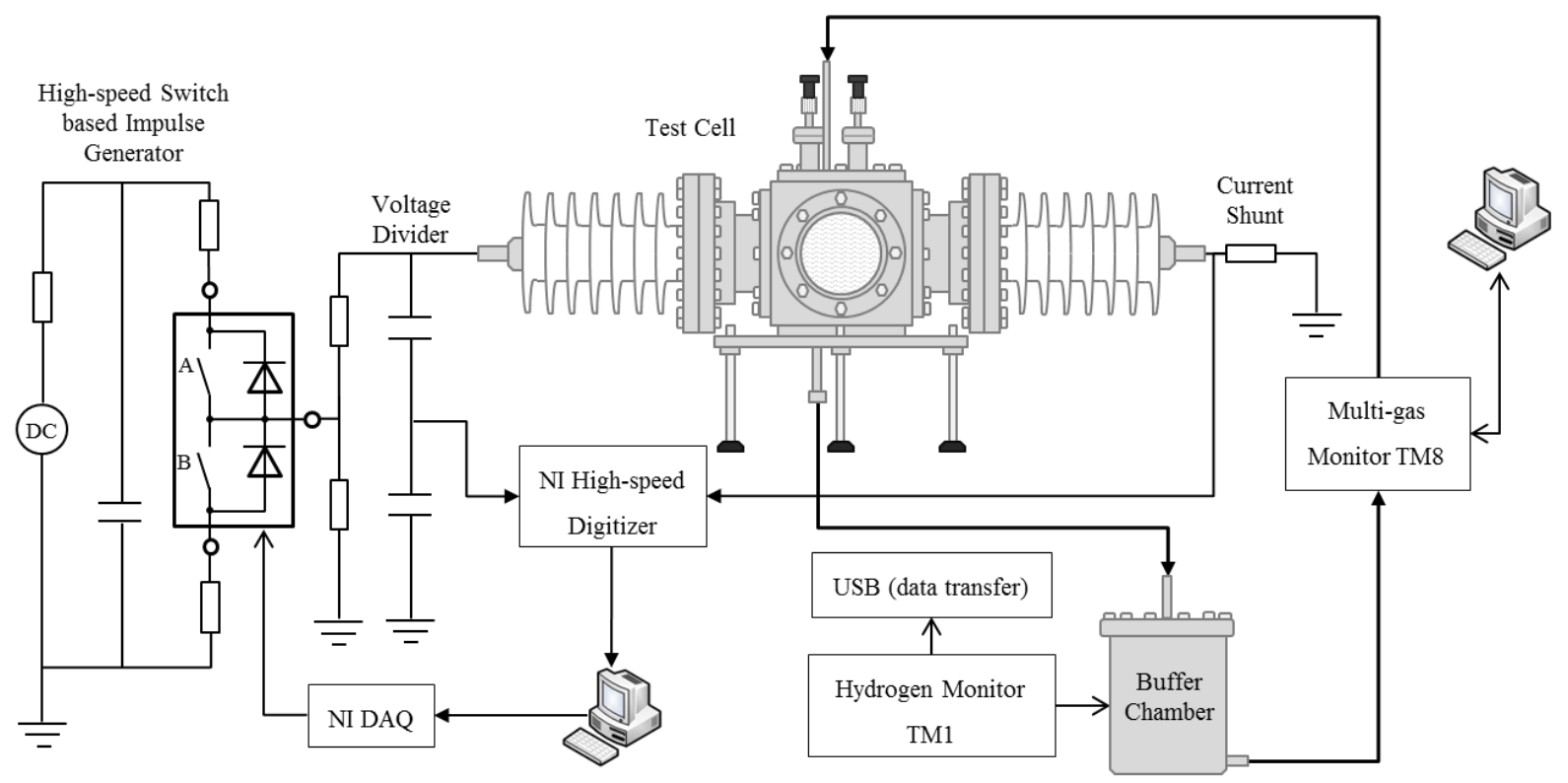

Figure 1. Experimental setup for spark-fault DGA measurements.

A point-to-plane electrode system was housed in a cubic stainless steel test cell with a volume of 1 litre. The point electrode with a tip radius of $50 \mu \mathrm{m}$ was produced using an electrochemical technique [11]. The brass plane electrode had a diameter of $20 \mathrm{~mm}$. The gap between the electrodes was fixed at $10 \mathrm{~mm}$.

The on-line DGA monitors, including a palladium sensor based Serveron TM1 hydrogen monitor and a gas chromatography (GC) based Serveron TM8 multi-gas monitor, were employed to measure fault gas generation [12]. A stainless steel buffer chamber with a volume of 1.2 litres was built to connect the hydrogen monitor to the oil circulation loop. The total volume of oil in the system was 2.7 litres.

\subsection{Test procedure}

A sample of Gemini X mineral oil was degassed and dehydrated in a vacuum oven, and then injected into the system by an oil pump. At the end of the oil filling process, a syringe was connected at the highest position of the oil loop in order to bleed air. The effect on hydrogen generation of various numbers of sparks up to 500, was investigated at the $99.9 \%$ breakdown voltage level. An additional set of measurements with 200 sparks was performed at a voltage level of 1.5 times the $99.9 \%$ breakdown voltage level. Each set of tests was repeated twice under the same conditions to confirm the repeatability of results. The time interval between consecutive sparks was set at 1 minute, and the oil was continuously circulated to help dispersion of breakdown by-products, e.g., gas bubbles and space charge. 


\subsection{Determination of breakdown voltage}

The applied voltage was set at $70 \%$ of the expected breakdown voltage and increased in 2 $\mathrm{kV}$ steps. 40 breakdowns of the oil sample were obtained to determine the probability distribution of the breakdown voltage as seen in Figure 2. The 50\% breakdown voltage was $35 \mathrm{kV}$ and the $99.9 \%$ breakdown voltage was $39 \mathrm{kV}$. A higher voltage level of $59 \mathrm{kV}$, i.e., 1.5 times the $99.9 \%$ breakdown voltage, was chosen in order to study the effects of increasing voltage on hydrogen generation.

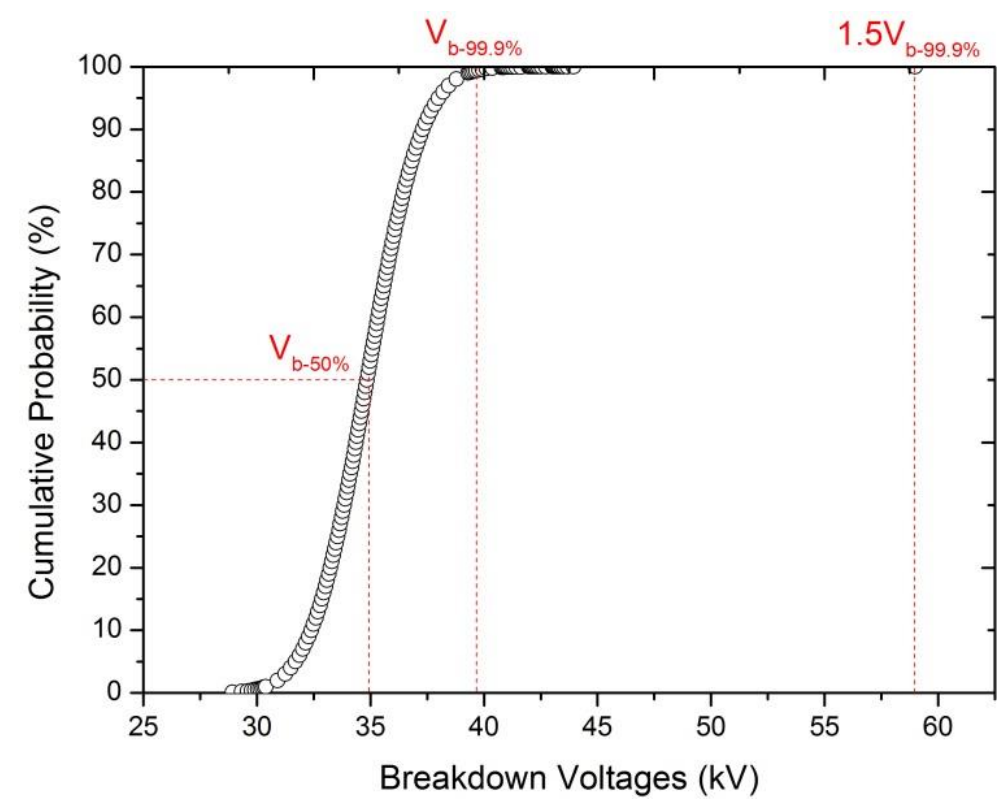

Figure 2. Normal cumulative distribution of breakdown voltage in mineral oil samples (10 mm point-plane electrode separation, 50 m point electrode tip radius).

\section{Data Processing}

\subsection{Hydrogen Monitoring}

An example of hydrogen production during the 500-spark test, conducted over a period of 720 minutes, is shown in Figure 3. The TM1 hydrogen monitor made one measurement every 30 minutes [13]. The electrical fault stress started at 0 minutes and ended at 500 minutes, and the dissolved hydrogen concentration in the oil gradually increased during this time. It continued to increase for a short period after the end of fault generation, and then reached a steady state, corresponding to the establishment of equilibrium between the gas and liquid phases in the system. In order to calculate the net hydrogen generation, the hydrogen readings were divided into three stages, namely background detection, spark fault period detection, and post-spark fault detection. Hydrogen generation due to the spark faults is then the difference between post-spark fault detection and background detection. 


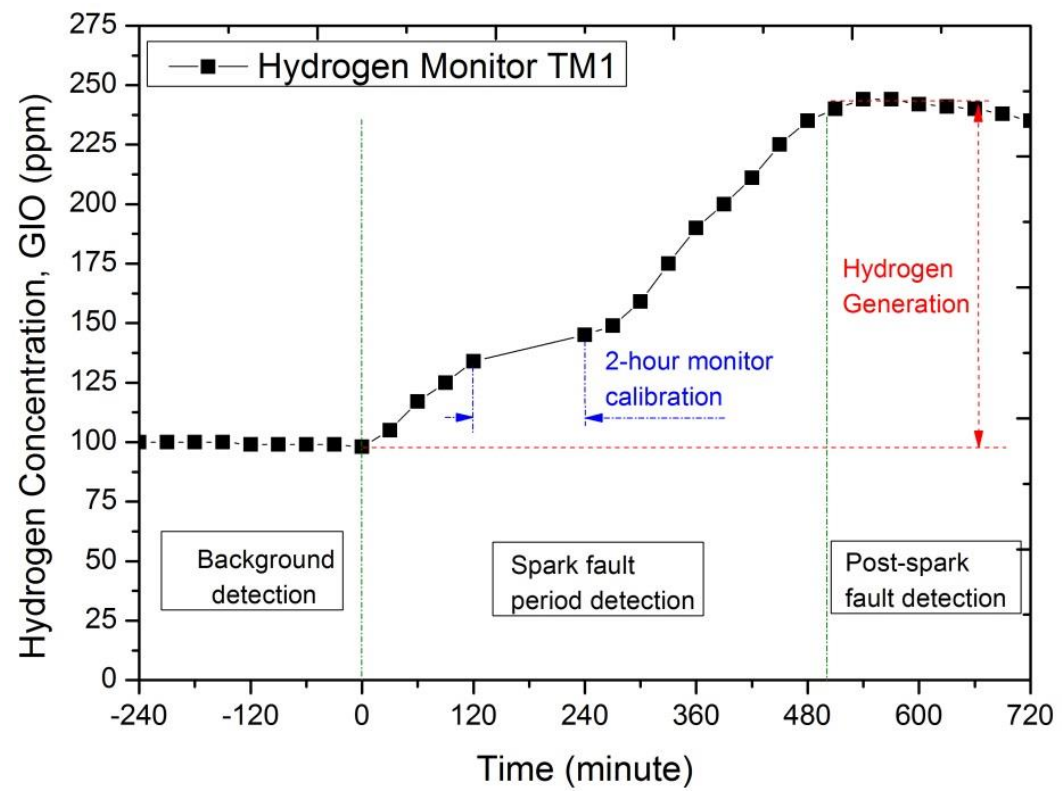

Figure 3. Hydrogen concentration in oil measured by the TMIhydrogen monitor during a 500 spark test.

3.2 Comparison of hydrogen concentrations measured by the TM1 monitor, the TM8 monitor and the laboratory DGA.

When the TM1 and TM8 measurements had been completed, the oil was sampled using gas-tight syringes and laboratory DGA measurements were performed. The fault gases were extracted using the headspace method, and analysed by laboratory-based gas chromatography. The TM1, TM8 and laboratory DGA data are compared in Table 1.

Table 1. Comparison of hydrogen concentrations measured by the TM1monitor, the TM8 monitor, and the laboratory DGA.

\begin{tabular}{|c|c|c|c|c|c|}
\hline \multirow{2}{*}{ Oil Sample } & \multicolumn{3}{|c|}{ Hydrogen Concentration (ppm) } & \multirow{2}{*}{$\begin{array}{c}\text { 100\% (TM1 - } \\
\text { TM8) /TM1 }\end{array}$} & $\begin{array}{c}\text { 100\% (TM1 - DGA) } \\
\text { /TM1 }\end{array}$ \\
\cline { 2 - 4 } & $\begin{array}{c}\text { TM1 } \\
\text { Hydrogen } \\
\text { Monitor }\end{array}$ & $\begin{array}{c}\text { TM8 } \\
\text { Multi-gas } \\
\text { Monitor }\end{array}$ & $\begin{array}{c}\text { Laboratory } \\
\text { DGA }\end{array}$ & & \\
\hline Sample 1 & 3 & 3 & 5 & $0 \%$ & $-67 \%$ \\
\hline Sample 2 & 8 & 8 & 11 & $0 \%$ & $-37 \%$ \\
\hline Sample 3 & 18 & 15 & 16 & $17 \%$ & $11 \%$ \\
\hline Sample 4 & 57 & 52 & 48 & $9 \%$ & $16 \%$ \\
\hline Sample 5 & 135 & 108 & 109 & $20 \%$ & $19 \%$ \\
\hline Sample 6 & 227 & 211 & 192 & $7 \%$ & $15 \%$ \\
\hline
\end{tabular}

The three sets of data are in good overall agreement. When the hydrogen concentration was greater than about $15 \mathrm{ppm}$, the TM1 reading was generally higher than the other two, but the differences did not exceed $20 \%$. When the hydrogen concentration was less than $15 \mathrm{ppm}$, large percentage differences were observed and presented in the table for consistency. 
However the absolute differences, within a few parts-per-million, are negligible in terms of practical application.

\section{Gas-In-Total Concentration and Energy Calculations}

The hydrogen monitor measures only the hydrogen concentration in the oil. However, when the oil circulation system incorporates a headspace volume, some of the hydrogen gas migrates into the headspace. Consequently the hydrogen concentration measured in the oil is not necessarily equal to the total hydrogen generation due to the spark fault. It is therefore necessary to calculate the gas-in-total (GIT) concentration using the gas-in-oil (GIO) concentration. In equations (1) to (4) below $C_{O}, C_{G}$ and $C_{T}$ are respectively the GIO, gas-ingas (GIG) and GIT concentrations, $M_{O}, M_{G}$ and $M_{T}$ are respectively the mass of GIO, GIG and GIT, $V_{O}$ and $V_{G}$ are respectively the volume of the oil and gas phase, and $K$ is the Ostwald (solubility) coefficient of hydrogen for the mineral oil. These equations are based on the conservation of mass law [10], [14].

$$
\begin{aligned}
& C_{O}=C_{G} * K \\
& M_{T}=M_{O}+M_{G} \\
& C_{T} * V_{O}=C_{O} * V_{O}+C_{G} * V_{G} \\
& C_{T}=C_{O}\left(1+\frac{1}{K} * \frac{V_{G}}{V_{O}}\right)
\end{aligned}
$$

(1) to (3) are used to deduce (4), which relates $C_{T}$ to $C_{O}$. $C_{O}$, the concentration of hydrogen in the oil in ppm, is measured using the DGA monitors. The headspace volume $V_{G}$ in the test system, including the DGA monitors, was estimated as $80 \mathrm{~mL}$, while the oil volume in the system $V_{O}$ is $2,700 \mathrm{~mL}$. $K$, the Ostwald (solubility) coefficient of hydrogen for the mineral oil, is temperature dependent. At the measurement temperature range $21 \pm 2{ }^{\circ} \mathrm{C}$ in the present study, $K$ was taken as 0.0433 [15].

The hydrogen concentration, expressed in ppm, is the ratio of the total hydrogen volume $(T H V)$ to the total oil volume. We want to correlate the $T H V$ (in $\mu \mathrm{L}$ ) and the spark fault energy $Q$ (in $\mathrm{J}$ ). The $T H V$ is defined in (5), and $Q$ is defined in (6).

$$
\begin{aligned}
& \text { THV }=C_{T} \times V_{O} \times 1000 \\
& Q=\int_{0}^{\infty} V I d t
\end{aligned}
$$


where $V$ and $I$ are respectively the voltage signal and the current signal recorded during spark faults. Typical voltage and current waveforms recorded during a spark are shown in Figure 4.
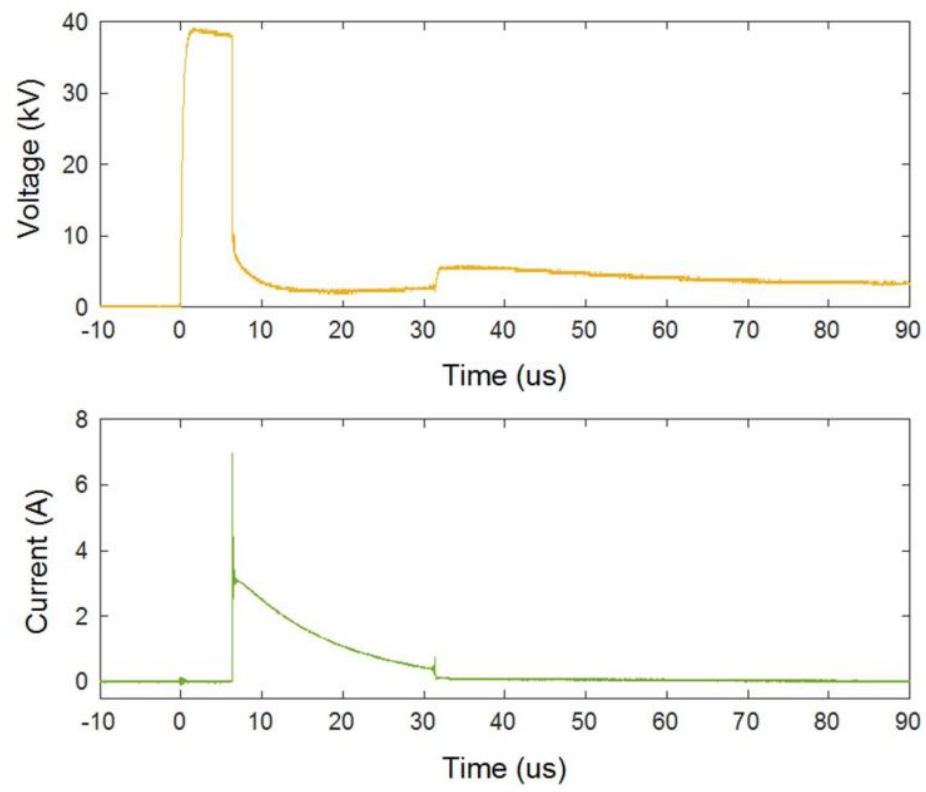

Figure 4. Typical voltage and current waveforms recorded during a spark at $99.9 \%$ breakdown voltage.

\section{Effect of Spark Numbers and Voltage Levels on Hydrogen Generation}

\subsection{Hydrogen Generation as a function of Spark Number}

Figure 5 shows hydrogen generation (GIT) as a function of the number of sparks recorded during two test runs at a breakdown voltage of $39 \mathrm{kV}$. The red dashed line is the average of the two test runs. GIT increased almost linearly with the number of sparks. This observation indicates that the hydrogen generation (GIT) per spark fault is almost constant under the test condition. It also indicates that there is no cumulative effect due to a large number of consecutive sparks, which can be attributed at least partly to the continuous oil circulation and the accurate control of the spark number and the time interval between consecutive sparks. 


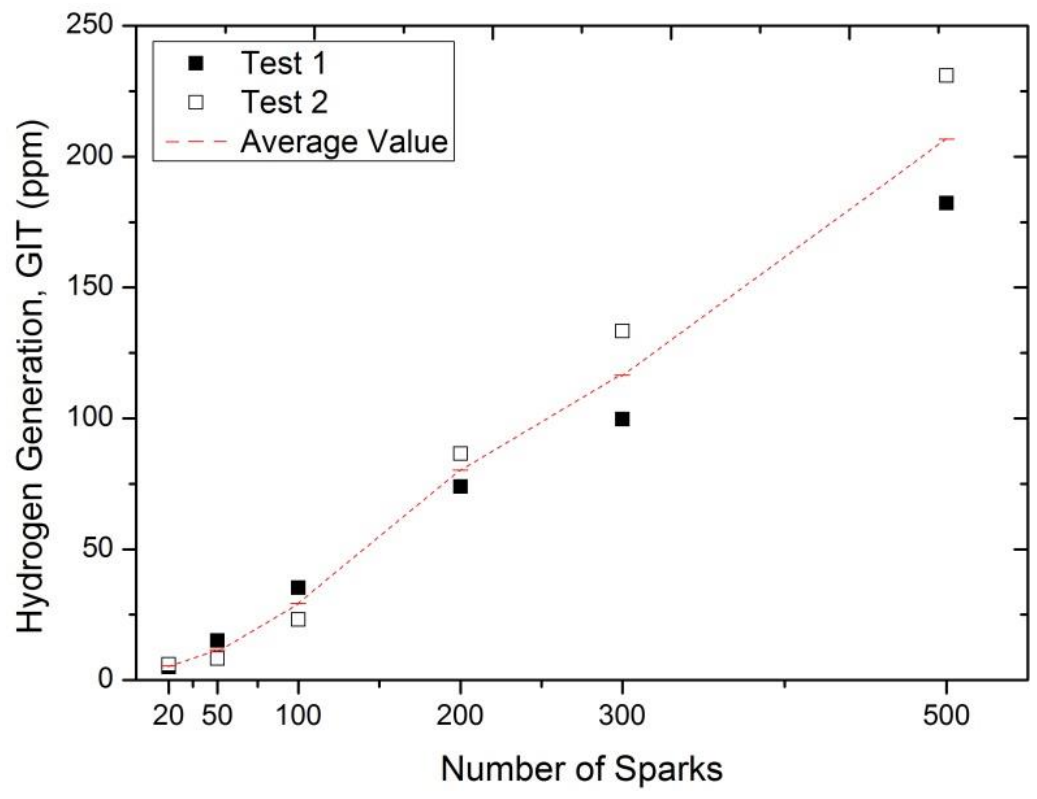

Figure 5. Hydrogen generation (GIT) as a function of the number of sparks at a breakdown voltage of $39 \mathrm{kV}$.

\subsection{Fault Energy and Generated Hydrogen Volume}

Fault gases including hydrogen are generated due to breakdown of the oil molecules under thermal energy and/or discharge fault energy. It is difficult to compare DGA results in the literature because the fault energy has rarely been quantified. Table 2 shows total hydrogen volume $T H V(\mu \mathrm{L})$, spark fault energy $Q(\mathrm{~J})$, and their ratio for various numbers of sparks, averaged over the two test runs. Since the hydrogen generation GIT increases approximately linearly with the number of sparks (Figure 5), for fixed oil volume, one would expect to see a similar increasing trend of $T H V$ with the number of sparks $((5))$. The spark fault energy $Q$ also increases linearly with the number of sparks ( $\mathrm{Q} /$ Number of sparks $=0.12+/-0.01$ ), which means the per-spark energy is constant and the sparks generated in the present study are repeatable. The ratio $T H V / Q$ stabilises at a level around $8.7 \mu L / J$ for 200 or more sparks, suggesting that the underlying hydrogen generation mechanism remains the same.

Table 2. Generated hydrogen volume per unit spark fault energy for various spark numbers, averaged over two test runs.

\begin{tabular}{|c|c|c|c|}
\hline $\begin{array}{c}\text { Number of } \\
\text { sparks }\end{array}$ & $\begin{array}{c}T H V \\
(\mu L)\end{array}$ & $\begin{array}{c}Q \\
(J)\end{array}$ & $\begin{array}{c}T H V / Q \\
(\mu L / J)\end{array}$ \\
\hline 20 & 14.8 & 2.48 & 5.97 \\
\hline 50 & 31.4 & 5.62 & 5.59 \\
\hline 100 & 78.9 & 11.28 & 6.99 \\
\hline 200 & 203.7 & 23.44 & 8.69 \\
\hline 300 & 314.6 & 36.03 & 8.73 \\
\hline
\end{tabular}




\begin{tabular}{|l|l|l|l|}
\hline 500 & 558.0 & 64.80 & 8.61 \\
\hline
\end{tabular}

\subsection{Hydrogen Generation and Breakdown Voltage Level}

An additional set of tests with 200 sparks was carried out at a higher voltage level of 59 $\mathrm{kV}$, i.e., 1.5 times the $99.9 \%$ breakdown voltage, to study the effects of increasing voltage on hydrogen generation. Figure 6 compares hydrogen generation (GIT) after 200 sparks at the two breakdown voltage levels. Clearly increased breakdown voltage results in greater hydrogen generation. Table 3 indicates that the increased hydrogen generation at the higher breakdown voltage level is due to the increased spark fault energy at that level. Surprisingly, $T H V / Q$ at $59 \mathrm{kV}$ is approximately $4 \%$ smaller than at $39 \mathrm{kV}$. However, this difference is probably within experimental uncertainty, suggesting that the underlying hydrogen generation mechanism remains similar for the tests carried out at the two breakdown voltage levels.

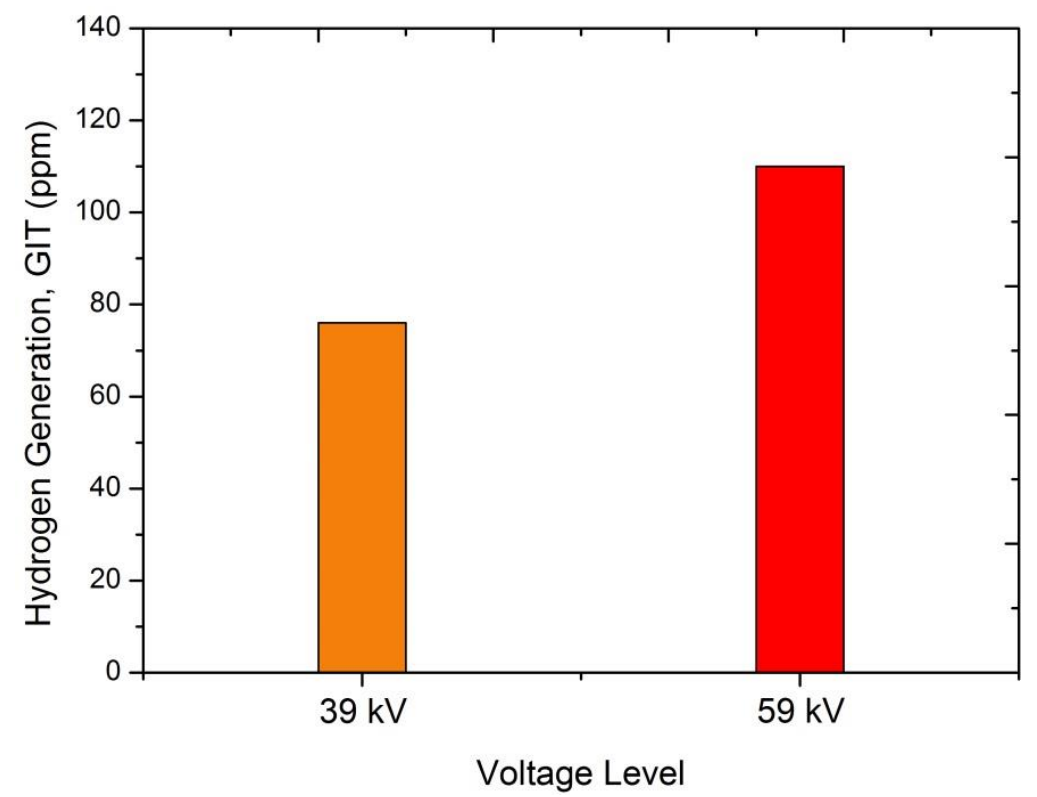

Figure 6. Hydrogen generation at two different voltage levels after 200 sparks.

Table 3. Generated hydrogen volume per unit fault energy at two breakdown voltage levels.

\begin{tabular}{|c|c|c|c|}
\hline $\begin{array}{c}\text { Voltage } \\
\text { level }\end{array}$ & $\begin{array}{c}T H V \\
(\mu \mathrm{L})\end{array}$ & $\begin{array}{c}Q \\
(\mathrm{~J})\end{array}$ & $\begin{array}{c}T H V / Q \\
(\mu \mathrm{L} / \mathrm{J})\end{array}$ \\
\hline $39 \mathrm{kV}$ & 203.7 & 23.44 & 8.69 \\
\hline $59 \mathrm{kV}$ & 298.5 & 35.90 & 8.31 \\
\hline
\end{tabular}

\section{Conclusion}


A DGA test platform based on a sealed circulating oil loop, with automatic spark fault control and data acquisition, was developed. The generation of hydrogen in a mineral oil was investigated under various electrical stress levels. The main findings were as follows:

(1) The hydrogen generation (GIT) increased almost linearly with the number of sparks, at least up to 500 .

(2) The generated hydrogen volume per unit spark fault energy was largely independent of the investigated number of sparks.

(3) The hydrogen generation (GIT) after 200 sparks increased with increasing breakdown voltage level, but the generated hydrogen volume per unit spark fault energy appeared to be largely independent of the investigated breakdown voltage level.

\section{ACKNOWLEDGEMENTS}

The authors would like to thank Qualitrol (Serveron) for financial and technical contributions to the project, and $\mathrm{TJ} \mid \mathrm{H} 2 \mathrm{~b}$ Analytical Services for laboratory measurements and other technical contributions. Special thanks are due to Mr Xiongfei Wang for advice and help on the use of online DGA monitors.

\section{REFERENCES}

[1] A. Febriyanto, and T. K. Saha, "Oil-immersed power transformers condition diagnosis with limited Dissolved Gas Analysis (DGA) data." Power Engineering Conference, Sydney, NSW, Australia, pp. 1-5, 2008

[2] IEC 60599, "Mineral Oil-impregnated Electrical Equipment in Service-Guide to the Interpretation of Dissolved and Free Gases Analysis," 2015.

[3] I. Khan, Z.D. Wang, I. Cotton, and S. Northcote, "Dissolved gas analysis of alternative fluids for power transformers," IEEE Electrical Insulation Magazine, vol. 23, no. 5, pp. 5-14, 2007.

[4] I. Khan, Z.D. Wang, J. Dai, I. Cotton and S. Northcote, "Fault gas generation in ester based transformer fluids and dissolved gas analysis (DGA)." International Conference on Condition Monitoring and Diagnosis, Beijing, China, pp. 909-913, 2008.

[5] N. Bakar, A. Abu-Siada, and S. Islam, "A review of dissolved gas analysis measurement and interpretation techniques," IEEE Electrical Insulation Magazine, vol. 30, no. 3, pp. 39-49, 2014.

[6] I. Pavlovsky, "Hydrogen sensor for oil transformer health monitoring." IEEE Conference on Nanotechnology, Arlington, TX, USA, pp. 211-213, 2008.

[7] Suwarno, "The Influence of arc on Dissolved Gases in Transformer Oils." 6th WSEAS International Conference on Power Systems, Lisbon, Portugal, pp. 498-501, 2006.

[8] M. Jovalekic, D. Vukovic, and S. Tenbohlen, "Dissolved gas analysis of alternative dielectric fluids under thermal and electrical stress." IEEE International Conference on Dielectric Liquids (ICDL), Trondheim, Norway, pp. 1-4, 2011. 
[10] Z.D. Wang, X. Wang, X. Yi, Sitao Li, and J.V. Hinshaw, "Gas generation in natural ester and mineral oil under partial discharge and sparking faults," IEEE Electrical Insulation Magazine, vol. 29, no. 5, pp. 62-70, 2013.

[11] W.-T. Chang, I.-S. Hwang, M.T. Chang, C.Y Lin and W.H Hsu, "Method of electrochemical etching of tungsten tips with controllable profiles," Review of Scientific Instruments, vol. 83, no. 8, pp. 083704, 2012.

[12] S. Singh, and M. Bandyopadhyay, "Dissolved gas analysis technique for incipient fault diagnosis in power transformers: A bibliographic survey," IEEE Electrical Insulation Magazine, vol. 26, no. 6, 2010.

[13] Serveron, "On-Line Transformer Monitor Operations and Maintenance GuideModel TM1," 2014.

[14] S. Tenbohlen, D. Vukovic and M. Jovalekic, "Dielectric performance and dissolved gas analysis of natural esters for application in power transformers." CIGRE SC D1 Colloquium, Hungary, Budapest, 2009.

[15] R. Battino, "The Ostwald coefficient of gas solubility," Fluid phase equilibria, vol. 15, no. 3, pp. 231-240, 1984.

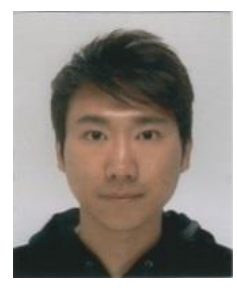

Jing Xiang obtained the B.Sc. degree in electrical and electronic engineering (2013) from the University of Manchester in the UK. Currently, he is a Ph.D student at the Power and Energy Division in the School of Electrical and Electronic Engineering at the University of Manchester. His research interests are pre-breakdown (streamer) and breakdown mechanisms in alternative transformer liquids under various voltage stresses.

Email: jing.xiang@postgrad.manchester.ac.uk

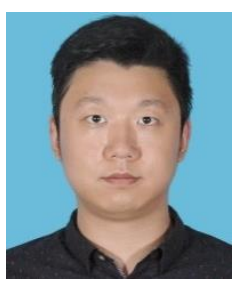

Xinyu Zhou obtained the B.Eng. degree in electrical and electronic engineering (2014) and the M.Sc. degree in advanced electrical power system engineering (2016) from the University of Manchester in the UK. He is currently working in Central Southern China Electric Power Design Institute (CSEPDI) of the China Power Engineering Consulting Group Corporation. Email: xinyu.zhou@postgrad.manchester.ac.uk

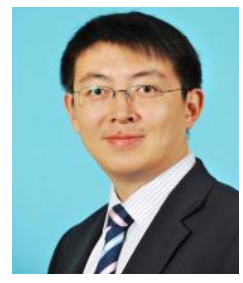

Qiang Liu (S'08-M'12) obtained the B.Eng. degree in electrical engineering (2005) and the M.Eng. degree in high voltage and electrical insulation (2008) from Xi'an Jiaotong University (XJTU) in China, and the Ph.D. degree in electrical power engineering (2011) from the University of Manchester in the UK. Currently, he is a Senior Lecturer in the Power and Energy Division in the School of Electrical and Electronic Engineering at the University of Manchester. His research interests are pre-breakdown and breakdown phenomena in liquids, alternative transformer liquids, streaming electrification, ageing of insulating materials, thermal modelling, transformer asset management and high voltage testing.

Email: qiang.liu@manchester.ac.uk

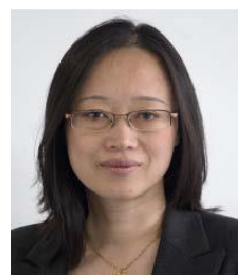

Zhongdong Wang received the B.Eng. and the M.Eng. degrees in high voltage engineering from the Tsinghua University of Beijing in 1991 and 1993 respectively, and the Ph.D. degree in electrical engineering from UMIST in 1999. Currently, she is a Professor of High Voltage Engineering in the Power and Energy Division of the School of Electrical and Electronic Engineering at the University of Manchester. Her current research interests include transformer condition monitoring, transformer modelling, FRA, simulation of transients, insulation ageing and alternative insulation materials for transformers.

Email: zhongdong.wang@ manchester.ac.uk 


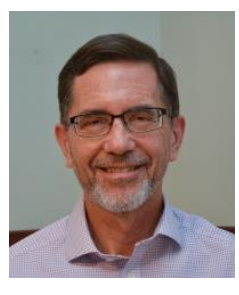

John V. Hinshaw received his Ph.D in Analytical Chemistry from Duke University in 1979. After working in laboratory instrument R\&D for 23 years, he joined Serveron (Beaverton, OR, USA) in 2002, where he develops online instrumentation as Senior Scientist. He actively serves on CIGRÉ Joint Working Group D1-A2.47, as the chair of ASTM Subcommittee E13.19 on Chromatography, and as a member of the USP Chemical Analysis Expert Committee.

Email: jhinshaw@qualitrolcorp.com

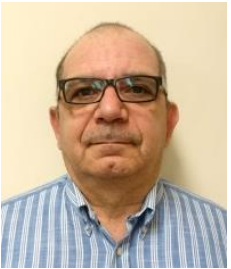

Pascal Mavrommatis received his first degree in Chemistry from Bedford College of London University in 1979 and Master's degree from North East London Polytechnic in Analytical Chemistry in 1981. After working in Motor Oil refineries for over 10 years and Salamon and Seaber Consultants for another 8 years, he joined the National Grid Laboratory and undertook a Ph.D at Surrey University in 1998. During this period, he was also appointed by National Grid to head the laboratories until 2003, and worked with Nynas for a further 9 years. In 2012, $\mathrm{TJh} 2 \mathrm{~b}$ acquired the laboratory services division and appointed him as Head of Research and Development \& Special Projects.

Email: Mavrommatis@tjh2b.com 